\title{
Spatiotemporal Assessment of Ecological Security in a Typical Steppe Ecoregion in Inner Mongolia
}

\author{
Xu Li ${ }^{1}$, Xiaobing Li ${ }^{1 *}$, Hong Wang ${ }^{1}$, Meng Zhang ${ }^{1}$, Fanjie Kong ${ }^{1}$, Guoqing Li ${ }^{2}$, \\ Meirong Tian ${ }^{3}$, Qi Huang ${ }^{1}$ \\ ${ }^{1}$ State Key Laboratory of Earth Surface Processes and Resource Ecology, Faculty of Geographical Science, \\ Beijing Normal University, Beijing, P.R. China \\ ${ }^{2}$ Institute of Geography and Planning, Ludong University, Yantai, Shandong, P.R. China \\ ${ }^{3}$ Nanjing Institute of Environmental Sciences, Ministry of Environmental Protection, Nanjing, P.R. China
}

Received: 15 June 2017

Accepted: 15 September 2017

\begin{abstract}
Ecological security is the comprehensive characterization of the noosystem's overall collaborative capacity in relation to human welfare within a whole society. Recent years, however, have witnessed the excessive exploitation of natural resources via anthropogenic activities that have consistently triggered or accelerated ecological deterioration. In addition, an adequate ecological security assessment has yet to be conducted in a steppe ecoregion, especially when considering that the steppe is the major ecoregion category in China. In this study, we selected a typical steppe ecoregion in Inner Mongolia, northern China, as a representative region to conduct a spatiotemporal assessment of ecological security from both global and local perspectives. Along with an evaluation indicator system constituting 25 separate indicators covering three different systems (society, economy, and nature), we applied an improved grey target decision-making method in the initial indicator conversion process. As it pertains to weight determination, we employed a weight calculation method that weighed all indicators synthetically. Research findings indicated that a progressive deterioration of ecological security has been observed in the typical steppe ecoregion of China from 1990 to 2014, with a decline in the security situation and even more severe deterioration observed from a local perspective than a global perspective. Social and economic systems, specifically an excessive rural population and unreasonable development (mainly grazing and mining), were the major factors that promoted ecological security deterioration, while the natural system has contributed only slightly to this deterioration.
\end{abstract}

Keywords: ecological security, typical steppe ecoregion, global perspective, local perspective, major factors

*e-mail: jeremy456@163.com 


\section{Introduction}

Ecological security refers to the total state of individual natural conditions and their surroundings in conjunction with conditions created by unsuitable anthropogenic activities [1], for which the sustainability of the collaboration capacity between humans and nature is emphasized, thereby providing supplementary elaboration on the sustainable development concept [2]. Ideally, ecological security requires the structural and functional dynamic stability of social-economic-natural complex ecosystems (namely noosystem) [3-5], where each individual subsystem maintains self-regulatory and self-repairing mechanisms and where synergistic evolution and the joint development of society, economy, and nature can be realized. However, it is inevitable that progressive anthropogenic activities (social and economic development) burden ecological environments and even cause degradation [6-8], which further degrades the collaborative capacity of the noosystem and eventually impairs current and future human welfare [9-11]. As a result, ecological security over the past couple of decades has aroused widespread attention and discussion in the academic community [12] for reasons regarding maintenance and realization of a virtuous cycles between humans and nature.

As the method that directly presents and describes ecological security situations, ecological security assessments have developed into the core and focus of ecological security research schemes and serve as a bridge between theoretical guidance and practice in this field [13]. In practice, interactions between various subsystems (as well as within a single subsystem) of the noosystem are too complex to be easily detected [14-16], but there are universal connections between processes and structures, and, to some extent, the detection and attainment of the latter is easier than the former, which is why structures can act as effective ways in which to speculate on the process itself [17-18]. As a result, regional ecological security assessments mostly conform to assessment processes associated with the building of indicator systems [19, $20]$, that is, the analysis of an indicator system as a way in which to ascertain how the structure infers the process [21-25]. In addition, a small part of the work is rooted in theories of ecological carrying capacities [26-27]. However, the existing assessment score didn't have good spatial expression, and the spatial heterogeneity of the noosystem has not been entirely favorably depicted [26, 28-30].Literature reviews over the past two decades have suggested that regional ecological security assessments have mostly been concentrated in urban areas where populations are centered [31-33], as well as grainproducing regions [34] or arid regions where ecological systems are fragile [35-36]. However, assessments and studies in other regions, such as steppe ecoregions, have been inadequate to date. As a result, assessment processes must be considerably improved in such regions. The steppe ecoregion constitutes roughly $40 \%$ of China's total territory and, subsequently, it is the nation's main terrestrial landscape [37]. In contrast, studies on regional security assessments of steppe ecoregions are still in the initial stage of development. Some studies have reported on various factors associated with the steppe ecoregion noosystem, such as climate change, grassland reclamation, overgrazing, and mining [38-41], which further affect part or all of the collaborative capacity of the system. However, the actual contribution of these factors on steppe ecoregions is subject to change through time and space. Furthermore, the ecological security indicator system of the steppe ecoregion that is currently available has not taken all these factors into account nor has it clarified their different contributions [26, 42].

Accordingly, this study conducted an investigation on the typical steppe ecoregion of Inner Mongolia, which is located in the core region of the steppe zone in northern China, where the local noosystem, anthropogenic activities, and eco-environmental issues are representative and typical of the ecoregion. Ever since the end of the 20th century, various typical steppe ecoregions have to some extent shown signs of degradation [43]. This has resulted from overgrazing, natural disasters, and an increasingly expanding mining industry, which has degraded the collaborative capacity of the local noosystem [44-45]. This study conducted a quantitative ecological security assessment on the noosystem of a typical steppe ecoregion to reveal changing characteristics of local ecological security situations and the contribution of various factors, which is intended to offer some support for ecological security monitoring and the evaluation of local steppe ecoregions or perhaps the whole steppe zone in northern China.

\section{Study Area}

The typical steppe ecoregion in the Inner Mongolian temperate zone is located in the true north of Beijing, the capital of China (see Fig. 1), over a longitudinal range from $113^{\circ} 27^{\prime}$ to $119^{\circ} 12^{\prime} \mathrm{E}$ and a latitudinal range from $43^{\circ} 3^{\prime}$ to $46^{\circ} 45^{\prime} \mathrm{N}$. The region borders Mongolia to the north and includes Xilinhot City, Abag Banner, and most of the West Ujimqin Banner and the East Ujimqin Banner.

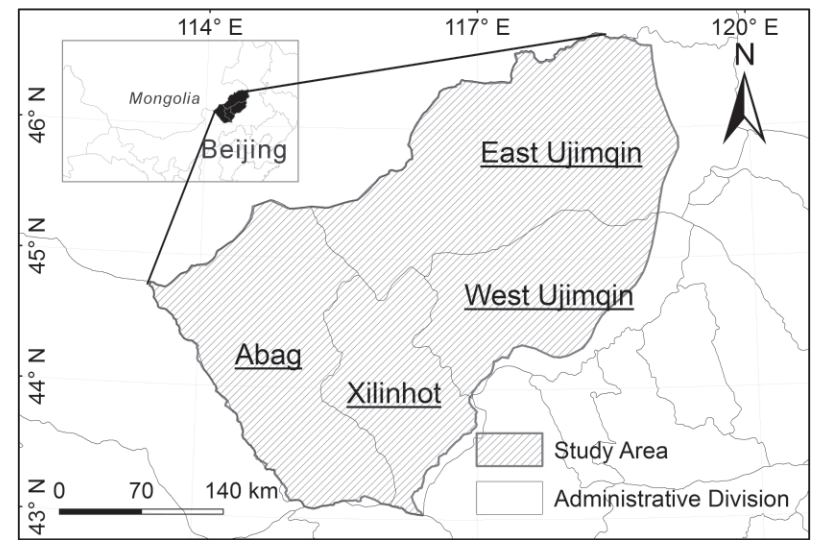

Fig. 1. Location of the study area. 
Table 1. Ecological security assessment indicator system (excluding water area).

\begin{tabular}{|c|c|c|c|c|}
\hline Target layer & $\begin{array}{l}\text { Criterion } \\
\text { layer }\end{array}$ & Indicator layer & Data sources & $\begin{array}{l}\text { Calculation of spatial } \\
\text { indicators }\end{array}$ \\
\hline \multirow{25}{*}{$\begin{array}{c}\text { Ecological } \\
\text { security } \\
\text { spatiotemporal } \\
\text { evaluation } \\
\text { (A) }\end{array}$} & \multirow{5}{*}{$\begin{array}{c}\text { Social } \\
\text { system } \\
\left(B_{1}\right)\end{array}$} & $\begin{array}{l}\text { Population pressure on the } \\
\text { environment }\left(C_{1}\right)\end{array}$ & [48] & Appendix A-(c) \\
\hline & & $\begin{array}{l}\text { Number of health workers per } \\
\text { millenary }\left(C_{2}\right)\end{array}$ & [48] & Appendix A-(a) \\
\hline & & $\begin{array}{l}\text { Business volume of post and telecoms } \\
\qquad\left(C_{3}\right)\end{array}$ & [48] & Appendix A-(a) \\
\hline & & $\begin{array}{c}\text { Per capita disposable income of } \\
\text { permanent residents of rural and } \\
\text { pastoral areas }\left(C_{4}\right)\end{array}$ & {$[48]$} & Appendix A-(b) \\
\hline & & Average wage of staff and workers $\left(C_{5}\right)$ & [48] & Appendix A-(a) \\
\hline & \multirow{9}{*}{$\begin{array}{l}\text { Economic } \\
\text { system } \\
\qquad\left(B_{2}\right)\end{array}$} & $\begin{array}{c}\text { Environmental pressure of primary } \\
\text { industry }\left(C_{6}\right) \\
\end{array}$ & [48] & Appendix A-(b) \\
\hline & & $\begin{array}{l}\text { Environmental pressure of secondary } \\
\text { industry }\left(C_{7}\right)\end{array}$ & {$[48]$} & Appendix A-(a) \\
\hline & & $\begin{array}{c}\text { Environmental pressure of tertiary } \\
\text { industry }\left(C_{8}\right)\end{array}$ & [48] & Appendix A-(b) \\
\hline & & Grazing pressure $\left(C_{9}\right)$ & [48]; NPP & Appendix A-(d) \\
\hline & & $\begin{array}{l}\text { Total power of agricultural machinery } \\
\qquad\left(C_{10}\right)\end{array}$ & {$[48]$} & Appendix A-(b) \\
\hline & & $\begin{array}{l}\text { Public budgetary financial revenue } \\
\qquad\left(C_{11}\right)\end{array}$ & {$[48]$} & Appendix A-(a) \\
\hline & & $\begin{array}{l}\text { Public budgetary financial expenditure } \\
\qquad\left(C_{12}\right)\end{array}$ & [48] & Appendix A-(a) \\
\hline & & Total investment of fixed assets $\left(C_{13}\right)$ & [48] & Appendix A-(a) \\
\hline & & $\begin{array}{l}\text { Total retail sales of consumer goods } \\
\qquad\left(C_{14}\right)\end{array}$ & {$[48]$} & Appendix A-(a) \\
\hline & \multirow{11}{*}{$\begin{array}{l}\text { Natural } \\
\text { system } \\
\left(B_{3}\right)\end{array}$} & Annual amount of solar radiation $\left(C_{15}\right)$ & data.cma.cn & [49] \\
\hline & & Average annual temperature $\left(C_{16}\right)$ & data.cma.cn & [49] \\
\hline & & $\begin{array}{c}\text { Annual } \geq 10^{\circ} \mathrm{C} \text { accumulated } \\
\text { temperature }\left(C_{17}\right)\end{array}$ & data.cma.cn & [49] \\
\hline & & Annual precipitation $\left(C_{18}\right)$ & data.cma.cn & [49] \\
\hline & & Annual arid index $\left(C_{19}\right)$ & data.cma.cn & $\begin{array}{c}\text { SPEI based on a 12-month } \\
\text { time span as the annual arid } \\
\text { index [50] }\end{array}$ \\
\hline & & Annual snow index $\left(C_{20}\right)$ & data.cma.cn & $\begin{array}{l}\text { Winter precipitation (from } \\
\text { November to February of the } \\
\text { following year) abnormity } \\
\text { percentage [51] }\end{array}$ \\
\hline & & $\begin{array}{l}\text { Normalized Difference Vegetation } \\
\text { Index (NDVI) }\left(C_{21}\right)\end{array}$ & $\begin{array}{l}\text { The Long sequence } \\
\text { NOAA/AVHRR satellite } \\
\text { product data set application } \\
\text { popularization program, } \\
\text { Key Technical Project } \\
\text { (No.: CMAGJ2011M64) of } \\
\text { the China Meteorological } \\
\text { Administration }\end{array}$ & \\
\hline & & Net Primary Productivity (NPP) $\left(C_{22}\right)$ & $\begin{array}{l}\text { NDVI and meteorological } \\
\text { data }\end{array}$ & {$[52]$} \\
\hline & & Vegetation cover $\left(C_{23}\right)$ & NDVI & [53] \\
\hline & & Fixed carbon content $\left(C_{24}\right)$ & NPP & $V_{C}=N P P \times 1.62[54]$ \\
\hline & & Amount of oxygen released $\left(C_{25}\right)$ & NPP & $V_{O}=N P P \times 1.2$ \\
\hline
\end{tabular}


It has a total land area of $96.6 \times 10^{3} \mathrm{~km}^{2}$, which is mainly highland, with an altitude of 740-1,720 m. The annual average temperature is $0-4^{\circ} \mathrm{C}$, and the temperature during the coldest month (January) ranges from approximately $-22^{\circ} \mathrm{C}$ to $-18^{\circ} \mathrm{C}$, while the temperature during the warmest month (July) is approximately $20^{\circ} \mathrm{C}$. Annual average precipitation fluctuates from 200 to $350 \mathrm{~mm}$, and more than $95 \%$ of the area belongs to the semiarid climate zone. It is abundant in grassland, biological, mineral, and tourism resources.

\section{Material and Methods}

\section{Ecological Security Indicator System}

By using the noosystem as an indicator framework and taking the state of practical local conditions into account, this study developed a holistic ecological security assessment indicator system designed for a typical steppe ecoregion, which is the most complete indicator system based on access data while also highlighting local primary demands.

As shown in Table 1, the indicator system omitted water bodies due to their small combined area. In view of the fact that social and economic development on the typical steppe ecoregion depends on and consumes the services and functions of the local ecosystem, the assessment indicators that were able to describe the society and economic status and scale were selected to build an indicator system. Those indicators present the density and intensity of natural resources that are consumed, such as population $\left(C_{1}\right)$ [44], educational level $\left(C_{2}\right)$ [46], income (the income of local people largely derived from the steppe: $C_{4}$ and $C_{5}$ ), regional GDP (all kinds of business activities are centered on the steppe: $C_{6}, C_{7}$, and $C_{8}$ ) [40], animal husbandry $\left(C_{9}\right)$, fiscal revenue and expenditure (they are in close connection with economic development: $C_{11}$ and $C_{12}$ ), and investment and consumption of the whole society $\left(C_{13}\right.$ and $\left.C_{14}\right)$. Moreover, natural indicators that show the state of the natural system from multiple aspects are not only the basic conditions for people to develop and utilize the typical steppe ecoregion but also are impacted by human actions. Drought $\left(C_{19}\right)$ and snowstorm $\left(C_{20}\right)$ are common local natural disasters [47]. Therefore, indicators reflecting the society, economy, and nature jointly constitute an indicator system that characterizes the ecological security of the local noosystem.

Finally, we processed all 25 indicators within the indicator system to make spatial data attributes uniform: the map projection was UTM (zone $50 \mathrm{~N}$ ), datum was WGS-84, spatial resolution was $1,000 \mathrm{~m}$, temporal resolution was annual, and the complete time series was from 1990 to 2014, where each year corresponded to 25 , indicating layers, and where each layer corresponded to 25 continuous years.

\section{Ecological Security Assessment Methods}

In this study we used the weighted aggregate indicator to calculate the ecological security situation index (ESSI) using the following formula:

$$
E S=\sum_{\alpha=1}^{25} I_{\alpha} \llbracket w_{\alpha}
$$

...where ES represents ESSI, and $I_{\alpha}$ and $w_{\alpha}$ are the indicator assessment score and corresponding weight, respectively. According to spatial data characteristics, this study stipulated that a single assessment object was the spatial range that an individual grid covered, which has an area of $1,000 \times 1,000 \mathrm{~m}^{2}\left(\approx 1 \mathrm{~km}^{2}\right)$. Accordingly, the typical steppe ecoregion was comprised of 96,553 assessment objects, where each object corresponded to 25 indicator attribute values for each of the 25 successive years.

\section{Indicator Assessment Score}

This study made grey target decisions [55] in the indicator assessment to evaluate the differences between the actual state and the optimal state.

The first step was to establish the indicator attribute sequences for the various assessment objects

$$
\begin{gathered}
\varphi_{i}^{t}=\left\{\varphi_{i}^{t}(k)\right\}=\left\{\varphi_{i}^{t}(1), \varphi_{i}^{t}(2), \cdots, \varphi_{i}^{t}(25)\right\} \\
i=1,2, \cdots, 96553 ; t=1990,1991, \cdots, 2014 ; k=1,2, \cdots, 25 .
\end{gathered}
$$

...where $\varphi_{i}^{t}$ represents the indicator attribute set of the $i^{\text {th }}$ assessment object for year $t$, and $\varphi_{i}^{t}(k)$ represents the $k^{\text {th }}$ indicator of the total 25 indicators of the $i^{\text {th }}$ assessment object for year $t$.

The second step was to establish the target sequences for each indicator:

$$
\varphi_{0}=\left\{\varphi_{0}(k)\right\}=\left\{\varphi_{0}(1), \varphi_{0}(2), \cdots, \varphi_{0}(25)\right\}
$$

...where $\varphi_{0}$ represents the target sequence, and $\varphi_{0}(k)$ represents the numerical value (target) of the $k^{\text {th }}$ indicator for the optimal state of ecological security. Target-setting principles are available as Appendix B.

The third step provided the grey target transformation:

$$
x_{i}^{t}(k)=\frac{\min \left\{\varphi_{i}^{t}(k), \varphi_{0}(k)\right\}}{\max \left\{\varphi_{i}^{t}(k), \varphi_{0}(k)\right\}}
$$

Herein, $x_{i}^{t}(k)$ represents results of initial indicator values and targets using grey target transformation.

The fourth step provides the target coefficient calculation: 


$$
\begin{gathered}
r_{i}^{t}(k)=\frac{\theta_{\min }+0.5 \theta_{\max }}{\Delta_{0 i}(k)+0.5 \theta_{\max }} \\
\Delta_{0 i}(k)=\left|x_{0}(k)-x_{i}^{t}(k)\right|=\left|1-x_{i}^{t}(k)\right| \\
=\left\{\left|1-x_{i}^{t}(1)\right|,\left|1-x_{i}^{t}(2)\right|, \cdots,\left|1-x_{i}^{t}(25)\right|\right\} \\
\theta_{\text {min }}=\min \Delta_{0 i}(k), \theta_{\text {max }}=\max \Delta_{0 i}(k)
\end{gathered}
$$

Herein, $r_{i}^{t}(k)$ represents the target coefficient of each indicator of the $i^{\text {th }}$ assessment object for year $t$, that is the indicator assessment score that corresponds to $I_{\alpha}$ in Eq. (1). $\Delta_{0 i}(k), \theta_{\min }$, and $\theta_{\max }$ are intermediate variables.

\section{Indicator Weight}

As it pertains to indicator weight, we used a method that Wang [56] developed. The advantage of this method was that it measured indicators of all assessment objects dynamically to determine their respective weights.

The first step was to standardize the indicator assessment score. Given that the closer the score was to one, the closer the state of ecological security would be, and we applied benefit-oriented standardized formulas bearing in mind that they were all benefit-oriented indicators:

$$
Z_{i}^{t}(k)=\frac{r_{i}^{t}(k)-\min y}{\max y-\min y}
$$

$$
\begin{gathered}
y=\left\{r_{1}^{1990}(k), r_{2}^{1990}(k), \cdots, r_{1}^{1991}(k), r_{2}^{1991}(k), \cdots, r_{9653}^{2014}(k)\right\} \\
t=1990,1991, \cdots, 2014 ; i=1,2, \cdots, n ; k=1,2, \cdots 25 .
\end{gathered}
$$

...where $Z_{i}^{t}(k)$ represents the standardized value of the $k^{\text {th }}$ indicator of the $i^{\text {th }}$ assessment object for year $t$, and $y$ represents the assessment score set of the $k^{\text {th }}$ indicator for all assessment objects.
The second step was to construct decision matrix $G_{i}$ of the $i^{\text {th }}$ assessment object, for which the standardized value for each year was an individual row vector:

$$
G_{i}=\left[\begin{array}{cccc}
Z_{i}^{1990}(1) & Z_{i}^{1990}(2) & \cdots & Z_{i}^{1990}(25) \\
Z_{i}^{1991}(1) & Z_{i}^{1991}(2) & \cdots & Z_{i}^{1991}(25) \\
\vdots & \vdots & \ddots & \vdots \\
Z_{i}^{2014}(1) & Z_{i}^{2014}(2) & \cdots & Z_{i}^{2014}(25)
\end{array}\right]
$$

When decision matrices of 1-96,553 assessment objects were constructed, $O$ was obtained using the calculation:

$$
O=\sum_{i=1}^{96553}\left(G_{i}\right)^{T} \sqsubset G_{i}
$$

The third step was to determine the maximum eigenvalue of matrix $O$ and the corresponding unitized eigenvector $W$ :

$$
W=\left\{W_{1}, W_{2}, \cdots W_{25}\right\}
$$

...where $W$ is the weight coefficient of the indicator assessment score that corresponds to $w_{\alpha}$ in Eq. (1).

\section{Ecological Security Assessment Perspectives}

Equation (3) is the target sequence of the grey target decision process, which specifically represents the absolute indicator values of the state of ecological security. Derived from assessment objects, target values in this study were indicator values taken from historical data of assessment objects near states of optimal ecological security.

\section{Global Perspective}

Distinguishing features of the global perspective are two-tiered. First, targets from the global perspective were

Table 2. Target sequence and indicator weight from a global perspective.

\begin{tabular}{|c|c|c|c|c|c|c|c|c|}
\hline Code & Target & Weight & Code & Target & Weight & Code & Target & Weight \\
\hline$C_{1}$ & 0.0039 & 0.0950 & $C_{10}$ & 0.0603 & 0.0579 & $C_{19}$ & {$[-1,1]$} & 0.0664 \\
\hline$C_{2}$ & 0.0384 & 0.1288 & $C_{11}$ & 0.2623 & 0.0266 & $C_{20}$ & {$[-50,50]$} & 0.0908 \\
\hline$C_{3}$ & 0.2805 & 0.0035 & $C_{12}$ & 0.2060 & 0.0250 & $C_{21}$ & 0.8300 & 0.0016 \\
\hline$C_{4}$ & 0.1172 & 0.0442 & $C_{13}$ & 0.4054 & 0.0133 & $C_{22}$ & 597.9745 & 0.0003 \\
\hline$C_{5}$ & 0.1593 & 0.0183 & $C_{14}$ & 0.1466 & 0.0191 & $C_{23}$ & 100 & 0.0027 \\
\hline$C_{6}$ & 0.1749 & 0.0063 & $C_{15}$ & {$[5462.1660,5987.1484]$} & 0.1145 & $C_{24}$ & 2051.9966 & 0.0003 \\
\hline$C_{7}$ & 0.3157 & 0.0199 & $C_{16}$ & {$[-0.9370,1.3212]$} & 0.0465 & $C_{25}$ & 1510.6724 & 0.0003 \\
\hline$C_{8}$ & 0.3600 & 0.0370 & $C_{17}$ & {$[1943.2593,2337.2349]$} & 0.0886 & & & \\
\hline$C_{9}$ & 10261.9530 & 0.0001 & $C_{18}$ & {$[229.8817,359.7970]$} & 0.0930 & & & \\
\hline
\end{tabular}




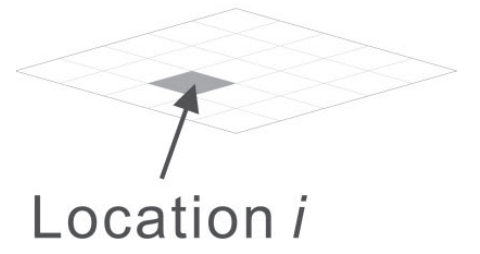

Location $i$

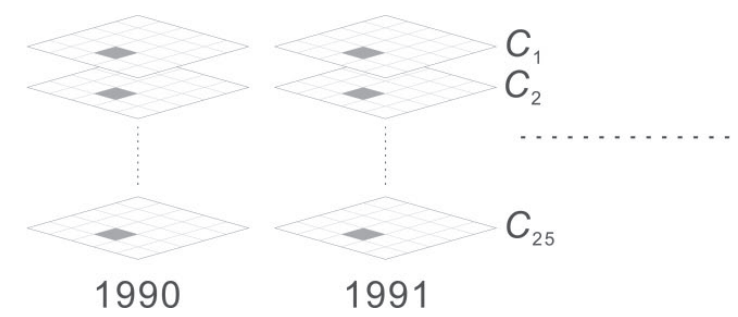

1991

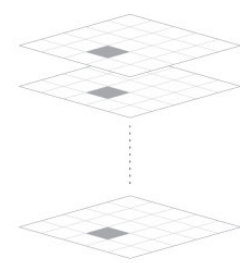

2014

Fig. 2. Spatial diagram of assessment objects from the local perspective.

derived from assessment objects that included all spatial and temporal dimensions that were then employed in the target sequence to calculate indicator assessment scores comparable between assessment objects, including all spatial and temporal dimensions. Second, indicator weights obtained based on assessment objects that include all spatial and temporal dimensions in conjunction with indicator assessment scores could be used to determine the ESSI (using Eq. (1)), which is also comparable between assessment objects, including all spatial and temporal dimensions. Owing to the uniform targets and weights, results of global assessments reflected the differences in the ecological security situation between the assessment objects.

As shown in Table 2, basic characteristics of the global perspective showed that there was only one target sequence group and one indicator weight group from a global perspective.

\section{Local Perspective}

Unlike the global perspective, assessment objects from the local perspective were confined to the same spatial locations and stressed the role that spatial heterogeneity played in targets and weights. As shown in Fig. 2, the $i^{\text {th }}$ assessment object existed throughout 1990 and 2014, from which its annual state was described by indicators $C_{1}$ through $C_{25}$. The origin of target sequences was when the $i^{\text {th }}$ assessment object was set to the time series that in turn made use of that target sequence for indicator assessment score estimations, which were then used to calculate the indicator weight during the local assessment process. The ESSI was finally calculated using the indicator assessment score and weight, and, as such, the calculation of assessment objects in other spatial locations could then be conducted. Predictably, each assessment target had a self-originated target sequence as well as a group of proprietary indicator weights, for which the final ESSI of each assessment object was only comparable within its own unique time series. Conversely, those from different spatial locations appeared incomparable, and this was due to incompatible target sequences and indicator weights.

Furthermore, weight calculations from the local perspective were partially adjusted due to changes in assessment objects, for the second step in particular, which, as shown below, was the most important adjustment.

The second step was the construction of decision matrix $G_{i}$ of the $i^{\text {th }}$ assessment object, and the standardization of the indicator value for each year into an individual row vector in a chronological sequence (the same as Eq. (10)).

If $O=\left(G_{i}\right)^{T} G_{i}$, the subsequent calculation is the same as above.

Given that there were 96,553 assessment objects (grids) in the typical steppe ecoregion, there were 96,553 corresponding groups of targets and weights from the local perspective, and their spatial distributions were the same as the various assessment objects. Fig. 3 provides the targets and weights of part of the indicators.

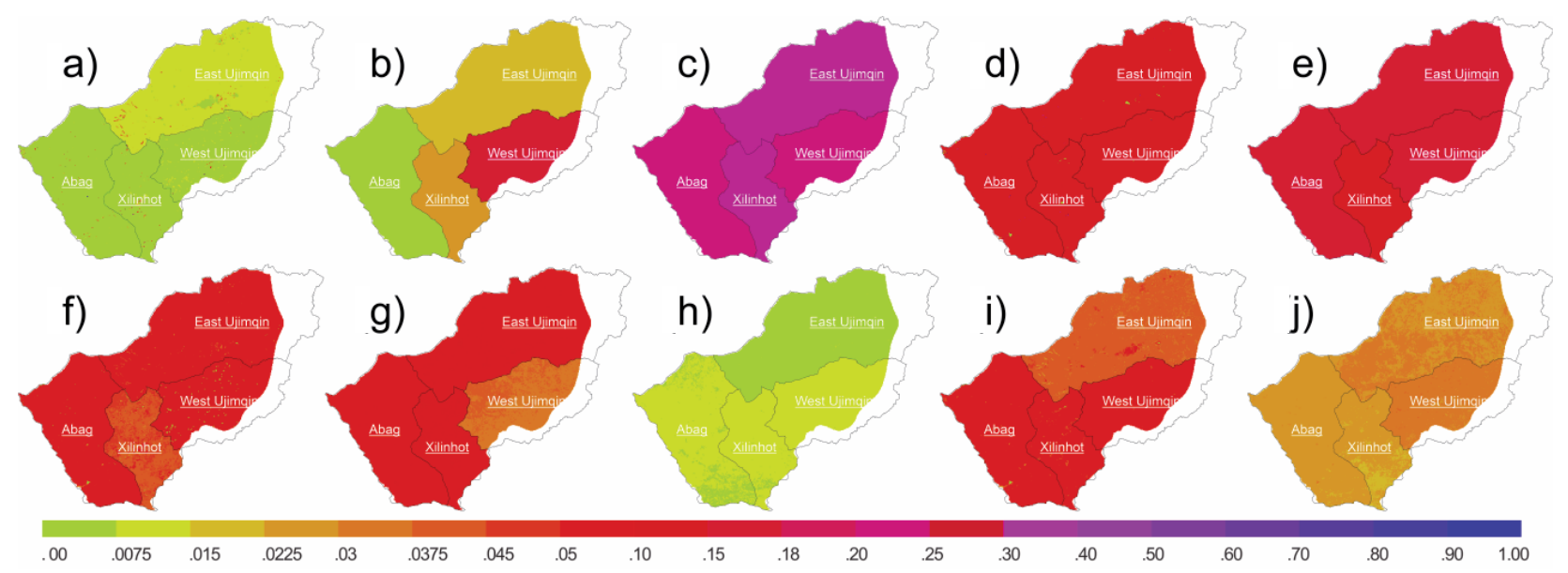

Fig. 3. Spatial distribution diagram of targets and weights of part of the indicators: (a-e) targets from $C_{1}$ through $C_{5}$, (f-j) weights from $C_{1}$ through $C_{5}$. 


\section{Ecological Security Assessment Levels}

The ESSI, with a value range of $[0,1]$, was a quantitative description of the gap between ecological security situations and optimal states, and the closer the values to its upper limit (1), the closer ecological security approached an optimal state. In this study, five levels of the ESSI were rated based on a quantitative investigation (see Appendix C), which was not only conducive to providing general information implied by the values, but also served as an important basis on which adjustment and recovery tasks could be conducted in the future.

\section{Results}

For the typical steppe ecoregion, Figs 4 and 5 provide the ESSI and situation level, respectively. In general, situation indexes from both assessment perspectives showed similar variations in the sharpness and pattern of decline; consequently, situation levels were also susceptible to movement between "excellent" and "bad." By contrast, results from the local perspective worsened even more dramatically than results from the global perspective, both globally and regionally.
From the global perspective, the ESSI declined at an annual rate of 0.00633 . The mean value of the ESSI from 1990 to 2014 was 0.8303 , which was rated "good," where max and min situation indexes were observed in 1990 (0.9460) and 2012 (0.7203), respectively. The situation index fell below 0.9 after 1993 and then to less than 0.8 since 2000 , during which time the ecological security situation was mostly at a "medium" level. The rate of decline in East Ujimqin Banner was slightly lower than in West Ujimqin Banner, both of which were higher than the average level. Given that long-term mean annual values of the ESSIs in both regions were 0.8245 and 0.8403 , respectively, the ecological security situation for accumulated years in West Ujimqin Banner was better than in East Ujimqin Banner. The annual rate of decline in the ESSI in Abag Banner, with a long-term mean annual value of 0.8356 , was roughly equal to the average level, which was better than East Ujimqin Banner and worse than West Ujimqin Banner. Among all typical steppe areas, Xilinhot City was the only area where the annual rate of decline was less than the average level, with a long-term mean annual value of 0.8227 , which was $71.09 \%$ that of West Ujimqin Banner. Not only was the ecological security situation of Xilinhot City worse than the typical steppe ecoregion as a whole, but it was also a)

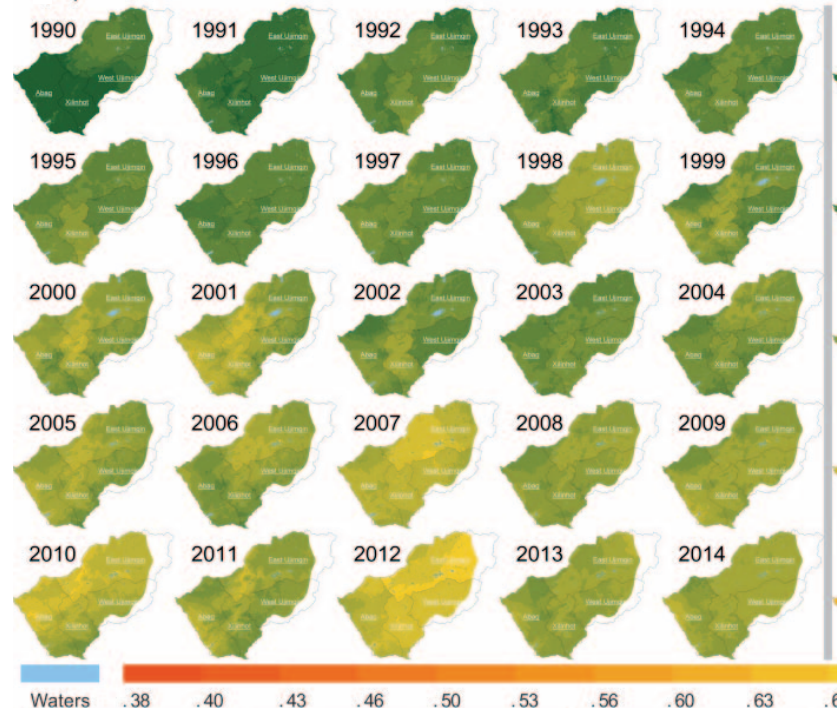

b)
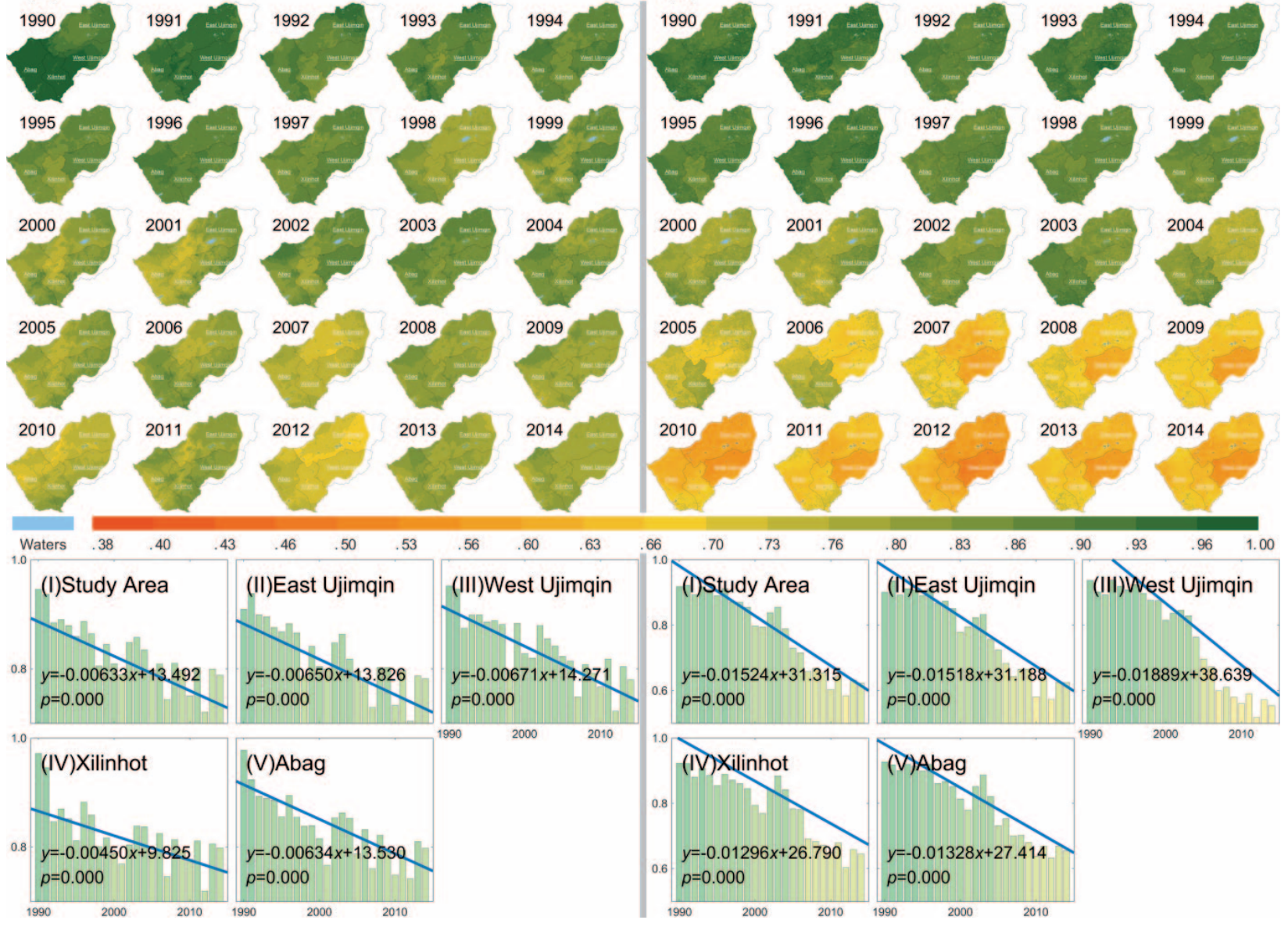

Fig. 4. Tendency in spatial distribution and variation for ESSIs of the typical steppe ecoregion; both sides of the grey solid line represent results from global a) and local b) perspectives. 
a)

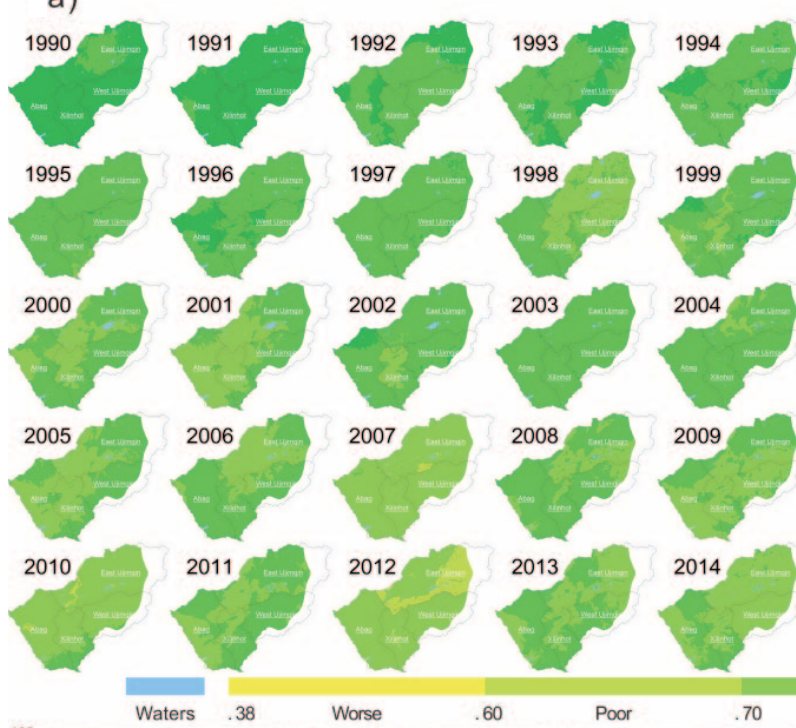

b)

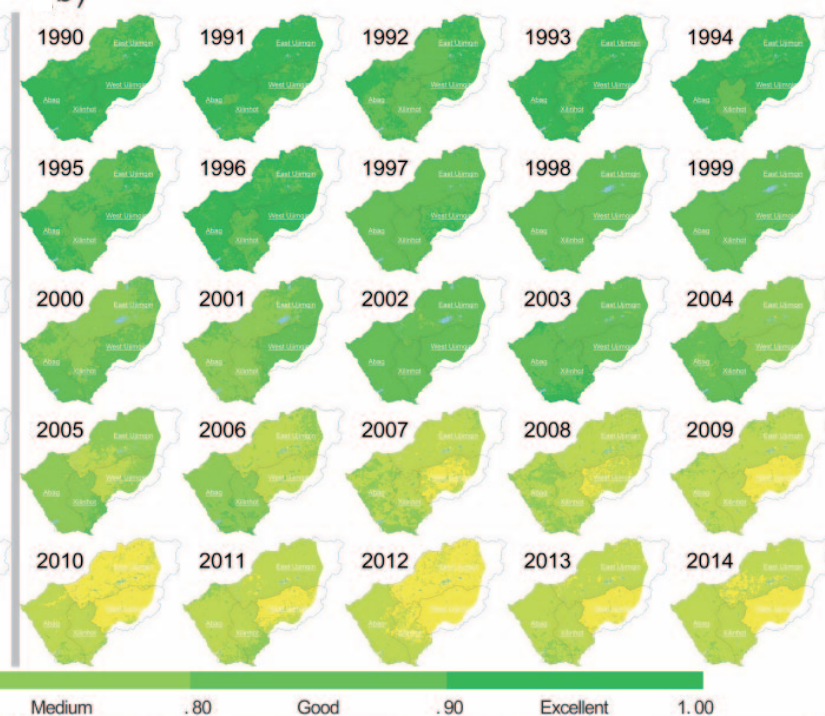

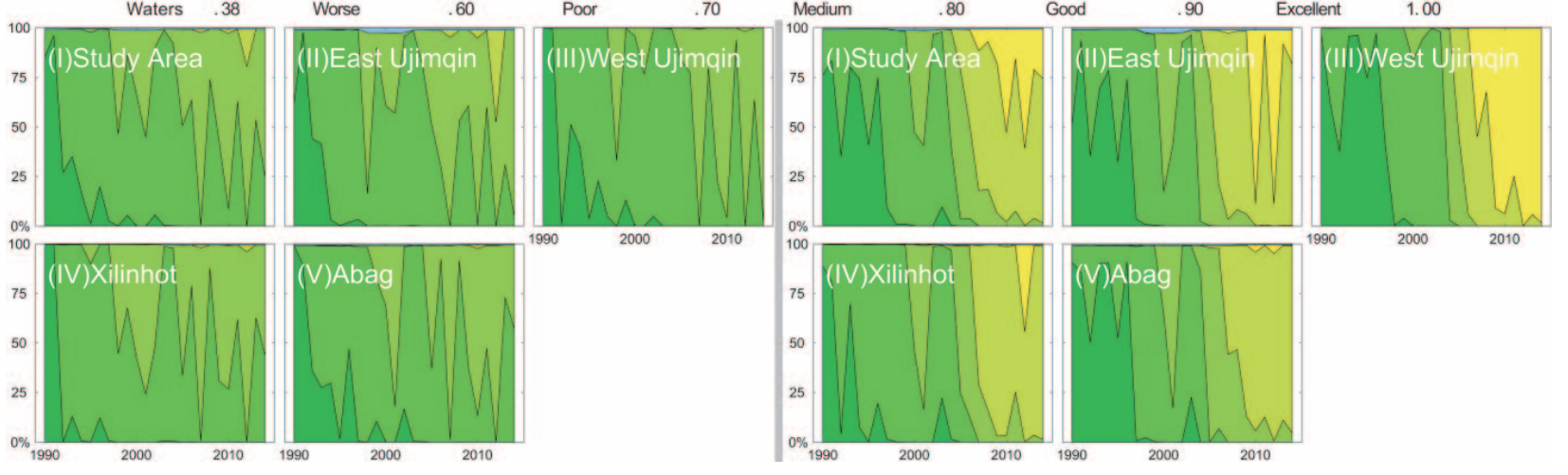

Fig. 5. Spatial distribution and area proportion of ecological security situation levels of the typical steppe ecoregion; both sides of the grey solid line represent results from global a) and local b) perspectives.

the worst among all areas investigated. With regard to the situation level, under conditions of a declining ecological security trend, ecological security situation levels of the various areas showed a general decline, for which the assessment concluded that the majority of areas constituted "excellent," "good," and "medium" levels. In the typical steppe ecoregion, $96.10 \%$ of all areas was "excellent" in 1991; however, in 2012 areas of "medium" and "bad" rose to $80.45 \%$ and $18.74 \%$, respectively, when the situation index was at its lowest level, and it was concentrated in East Ujimqin Banner.

This study used the local perspective to study changes in assessment objects, that is, a valuation of objects of ecological security situations during different times and under their own optimal states. Accordingly, indexes simply represent the degree that objects deviated from their optimal states. From the local perspective, the annual declining rate of the typical steppe ecoregion was 0.01524 , which was greater by a factor of 2.41 compared to the global perspective. The mean value of the ESSI over a 25 -year period was 0.7819 , which is to say, it was at a "medium" level, where max and min indexes were observed in 1991 (0.9223) and 2012 (0.5841), respectively. The ESSI fell below 0.9 after 1996 and fell below 0.7 after 2006, during which time situation levels were observed to be mostly "poor" and "bad." Among all the areas that constitute the typical steppe ecoregion, West Ujimqin Banner was the only one where the annual rate of decline (0.01889) was higher than the average level. The long-term mean annual ESSI of this region was 0.7647 , which was lower than the average, indicating that local ecological degradation in this area was worse than the average level. The rate of decline in East Ujimqin Banner, for which the ESSI of accumulated years was 0.7742 , was slightly lower than the average level but higher than West Ujimqin Banner, suggesting that ecological degradation in East Ujimqin Banner was worse than the average level but better than in West Ujimqin Banner. The rates of decline in Xilinhot City (with the lowest rate) and Abag Banner (with the lowest ecological degradation level) were $85.04 \%$ and $87.14 \%$ compared to the average level, respectively. Moreover, long-term mean annual values of the ESSIs in both areas were 0.7926 and 0.7984 , respectively, both of which were higher than the average level, which is evidence that ecological degradation levels in both areas were lower than the average level. For situation levels, the assessment showed that the majority of levels were "poor" and "bad", and this was because the rate of decline fell faster under the local perspective, for which both levels covered greater than half of the area after 2006. Of all the 
a)

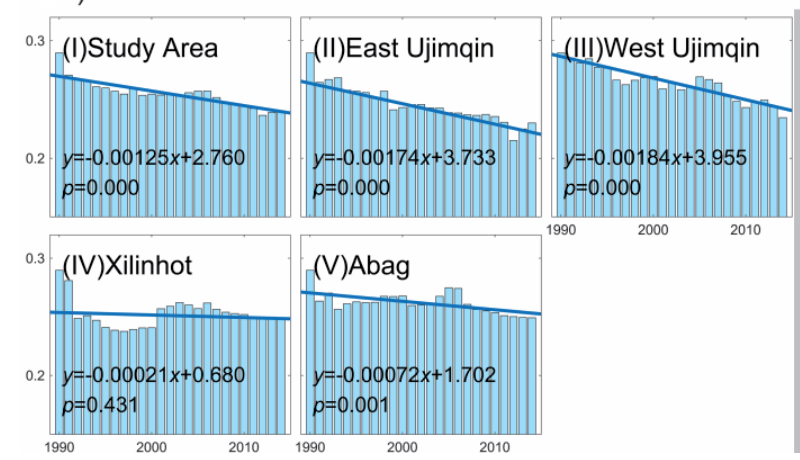

b)

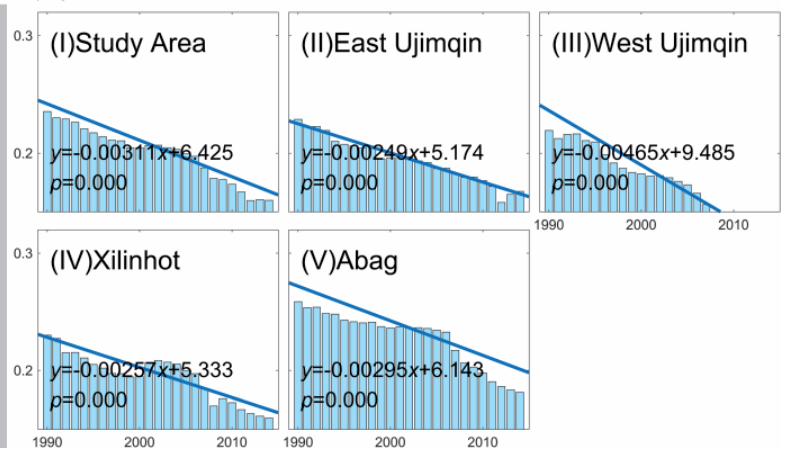

Fig. 6. Tendency in variation of time series of index components in the social system.

areas, the ecological security situation fell most sharply in East Ujimqin Banner and West Ujimqin Banner.

\section{Effects of Influencing Factors}

\section{Criterion Layer}

According to the indicator system in Table 1, the ESSI consisted of index components of three subsystems, that is, the social system, the economic system, and the natural system, which showed that the tendency in variation of the comprehensive situation index could decompose on a subsystem level in order to reveal the contribution in changes of various subsystems to general changes. As shown in Fig. 6, the trend in time series under the local perspective was greater by a factor of approximately 2 to 3 compared to the global perspective. From the global perspective, Xilinhot City was the only area where the trend in time series for the index component of the social system was not significant ( $p>0.05$ ), while the other areas reached significant levels. Table 3 provides the tendency in variation of time series of index components in the other subsystems.

Table 3 shows that the assessment did not detect a tendency toward significant variation for index components in the natural system. However, this study found widespread significant declining tendencies in index components for the social and economic systems, both of which constituted the major motivating factors that exacerbated ecological security. Tendencies in variation of the index components in the social and economic systems under the global perspective were -0.00125 and -0.00439 , respectively, which were $19.75 \%$ and $69.35 \%$ of variation for all situation indexes, respectively, indicating that both systems contributed $19.75 \%$ and $69.35 \%$ separately and $89.10 \%$ in total. In a similar fashion, the rate of contribution of the social and economic systems in East Ujimqin Banner, West Ujimqin Banner, Xilinhot City, and Abag Banner were $94.92 \%, 91.06 \%, 90.89 \%$, and $81.86 \%$. Similarly, tendencies in variation of index components in the social and economic systems under the local perspective were -0.00311 and -0.01103 , respectively, which contributed $20.41 \%$ and $72.38 \%$ of variation in all situation indexes, respectively, which aggregated the rate of contribution to $92.78 \%$. For the criterion layer, East Ujimqin Banner and West Ujimqin Banner showed higher rates of contribution than the average level ( $96.05 \%$ and $93.22 \%$, respectively). The rates of contribution in Xilinhot City and Abag Banner were lower than the average level $(89.04 \%$ and $92.02 \%$, respectively). A comparison between the contribution rates of the various areas on the criterion layer showed that the economic system, whose rates of contribution were often greater than a factor of 2 to 5 (compared to the social system), played a more significant role in the worsening ecological security.

Table 3. Tendency in variation of time series of index components in the criterion layer

\begin{tabular}{|c|c|c|c|c|c|c|c|c|c|c|}
\hline & \multicolumn{4}{|c|}{ Global perspective } & \multicolumn{4}{c|}{ Local perspective } \\
\cline { 2 - 11 } & $\begin{array}{c}\text { Study } \\
\text { Area }\end{array}$ & $\begin{array}{c}\text { East } \\
\text { Ujimqin } \\
\text { Banner }\end{array}$ & $\begin{array}{c}\text { West } \\
\text { Ujimqin } \\
\text { Banner }\end{array}$ & $\begin{array}{c}\text { Xilinhot } \\
\text { City }\end{array}$ & $\begin{array}{c}\text { Abag } \\
\text { Banner }\end{array}$ & $\begin{array}{c}\text { Study } \\
\text { Area }\end{array}$ & $\begin{array}{c}\text { East } \\
\text { Ujimqin } \\
\text { Banner }\end{array}$ & $\begin{array}{c}\text { West } \\
\text { Ujimqin } \\
\text { Banner }\end{array}$ & $\begin{array}{c}\text { Xilinhot } \\
\text { City }\end{array}$ & $\begin{array}{c}\text { Abag } \\
\text { Banner }\end{array}$ \\
\hline The noosystem & $\mathbf{- 0 . 0 0 6 3 3}$ & $\mathbf{- 0 . 0 0 6 5 0}$ & $\mathbf{- 0 . 0 0 6 7 1}$ & $\mathbf{- 0 . 0 0 4 5 0}$ & $\mathbf{- 0 . 0 0 6 3 4}$ & $\mathbf{- 0 . 0 1 5 2 4}$ & $\mathbf{- 0 . 0 1 5 1 8}$ & $\mathbf{- 0 . 0 1 8 8 9}$ & $\mathbf{- 0 . 0 1 2 9 6}$ & $\mathbf{- 0 . 0 1 3 2 8}$ \\
\hline Social system & $\mathbf{- 0 . 0 0 1 2 5}$ & $\mathbf{- 0 . 0 0 1 7 4}$ & $\mathbf{- 0 . 0 0 1 8 4}$ & -0.00021 & $\mathbf{- 0 . 0 0 0 7 2}$ & $\mathbf{- 0 . 0 0 3 1 1}$ & $\mathbf{- 0 . 0 0 2 4 9}$ & $\mathbf{- 0 . 0 0 4 6 5}$ & $\mathbf{- 0 . 0 0 2 5 7}$ & $\mathbf{- 0 . 0 0 2 9 5}$ \\
\hline Economic system & $\mathbf{- 0 . 0 0 4 3 9}$ & $\mathbf{- 0 . 0 0 4 4 3}$ & $\mathbf{- 0 . 0 0 4 2 7}$ & $\mathbf{- 0 . 0 0 4 0 9}$ & $\mathbf{- 0 . 0 0 4 4 7}$ & $\mathbf{- 0 . 0 1 1 0 3}$ & $\mathbf{- 0 . 0 1 2 0 9}$ & $\mathbf{- 0 . 0 1 2 9 6}$ & $\mathbf{- 0 . 0 0 8 9 7}$ & $\mathbf{- 0 . 0 0 9 2 7}$ \\
\hline Natural system & -0.00041 & -0.00036 & -0.00034 & -0.00063 & -0.00122 & -0.00067 & -0.00031 & -0.00138 & -0.00107 & -0.00044 \\
\hline
\end{tabular}

Note: Bolded text shows that the variation rate passed significance test $(\mathrm{p}<0.05)$ 


\section{Indicator Layer}

In fact, the ESSI, which was composed from various subsystems, was also fashioned from amassing each absolute indicator, which was the reason why, in this study, we followed this process with an analytical appraisal on the tendency of time series to investigate the effects of each situation index factor and to study variables of situation indexes on indicator layers to better monitor and identify the various factors that affect changes in ecological security.

Fig. 7 shows the tendency in variation of time series of index components for different indicators under both perspectives, and that certain tendencies failed to pass the significance test. The rate of contribution of indicator layers in the study area of the typical steppe ecoregion reached $93.17 \%$ from the global perspective, that is, as much as $93.17 \%$ of the effect could be retraced to specific indicators, whose contribution rate (top 10) could be classified in descending order from the total power of agricultural machinery $\left(C_{10} ; 15.19 \%\right)>$ environmental pressure of tertiary industry $\left(C_{8} ; 14.70 \%\right)>$ per capita disposable income of permanent residents on rural and pastoral areas $\left(C_{4} ; 14.59 \%\right)>$ public budgetary financial revenue $\left(C_{11} ; 10.20 \%\right)>$ public budgetary financial expenditure $\left(C_{12} ; 8.93 \%\right)>$ environmental pressure of secondary industry $\left(C_{7} ; 7.55 \%\right)>$ average wages of staff and workers $\left(C_{5} ; 6.55 \%\right)>$ total retail sales of consumer goods $\left(C_{14} ; 5.33 \%\right)>$ total investment in fixed assets $\left(C_{13} ; 4.94 \%\right)>$ annual $\geq 10^{\circ} \mathrm{C}$ accumulated temperature $\left(C_{17} ; 4.52 \%\right)$. The rates of contribution for the remaining significant indicators were almost 0 . The fact that excessive income growth of rural and urban residents $\left(C_{4}\right.$ and $\left.C_{5}\right)$ would promote the intensification of steppe exploitation and that indicators that originated from the economic system contributed the most to ecological security degradation indicated that societal and economic overdevelopment had taken a toll on the noosystem's collaborative capacity. Of all regions, the rate of contribution of the indicator layer in East Ujimqin Banner was slightly higher than the average level, with contribution rates in West Ujimqin Banner, Xilinhot City, and Abag Banner of $86.25 \%$,
$78.76 \%$, and $87.29 \%$, respectively. The top 10 indicators that impacted ecological security in the typical steppe ecoregion were basically the indicators that played crucial roles in the various areas, but with slightly varied effects. Population pressure on the environment did not constitute a significant factor in the typical steppe ecoregion; however, it reflected the unbalanced social development between various other areas. For example, the minority of local herdsmen did not place a heavy burden on the ecoenvironment since the urbanization rate of Xilinhot City had already reached more than $90 \%$, for which population pressure on the environment acted as the major force that contained rather than boosted deterioration in local ecological security, with a contribution rate of $-37.45 \%$, whose index had the maximum effect in this area as it did in Abag Banner (-4.12\%). However, rates of contribution of population pressure on the environment in East Ujimqin Banner and West Ujimqin Banner were 10.49\% and $3.95 \%$, respectively, since herdsmen in both regions had long constituted nearly $50 \%$ of the population, which was the reason why the steppe population showed no evidence of a reduction [44], for which population pressure on the environment in both areas became the major factors that worsened ecological security.

Compared to the global perspective, declining rates appeared sharper under the local perspective, which, in some indicators, could be greater by a factor of 2 to 4 compared to the global perspective. From the local perspective, the contribution rate of the indicator layer in the typical steppe ecoregion was $95.10 \%$, which originated from a total economic system of $72.26 \%$. Moreover, the top $10 \mathrm{key}$ indicators in descending order were public budgetary financial revenue $\left(C_{11}\right.$; $15.58 \%)>$ public budgetary financial expenditure $\left(C_{12}\right.$; $15.51 \%)>$ environmental pressure of secondary industry $\left(C_{7} ; 11.90 \%\right)>$ total investment in fixed assets $\left(C_{13}\right.$; $9.65 \%)>$ environmental pressure of tertiary industry $\left(C_{8}\right.$; $9.04 \%)>$ per capita disposable income of permanent residents of rural and pastoral areas $\left(C_{4} ; 8.78 \%\right)>$ average wages of staff and workers $\left(C_{5} ; 7.74 \%\right)>$ total retail sales of consumer goods $\left(C_{14} ; 7.24 \%\right)>$ total power of agricultural machinery $\left(C_{10} ; 3.67 \%\right)>$ vegetation coverage

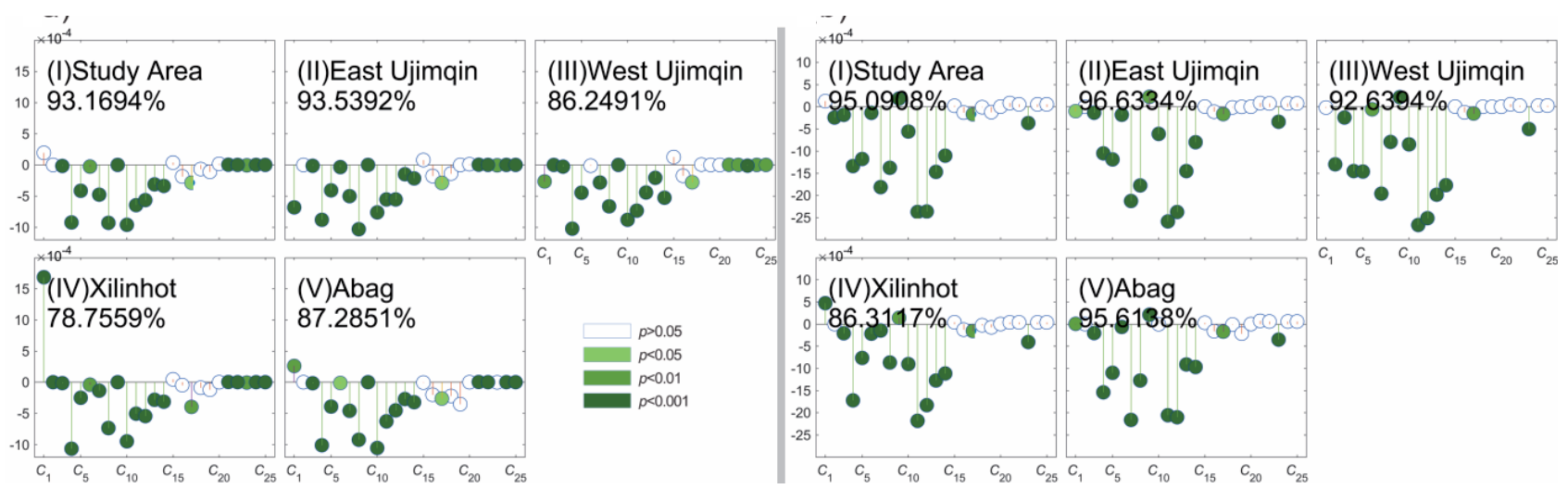

Fig. 7. Tendency in variation of time series of index components in the indicator layer (unitless), the values came from the slopes; percentages represent the accumulated contribution rates for tendencies of significant variation in the index 
$\left(C_{23} ; 2.42 \%\right)$. The rates of contribution of the remaining significant indicators were approximately $1 \%$. Unlike the global perspective, no tendency in variation of NDVI, NPP, fixed carbon content, and the amount of oxygen released reached a significant level. Of all areas, rates of contribution of the indicator layer in East Ujimqin Banner and Abag Banner were slightly higher than the average level, whereas West Ujimqin Banner (92.63\%) and Xilinhot City $(86.31 \%)$ exhibited the opposite trend. Indicators that impacted ecological security in the typical steppe ecoregion were basically the indicators that played key roles in the various areas of the ecoregion, but differences in these effects were less than those from the global perspective. For instance, the public budgetary financial expenditure $\left(C_{12}\right)$, whose $15 \%$ rate of contribution ranked second among all key indicators in the various areas. Similar to the global perspective, population pressure on the environment remained unchanged in the various areas, but with a decreased effect. For example, population pressure was the ninth key indicator of Xilinhot City, and its rate of contribution fell as low as $-3.65 \%$ and almost $0 \%$, or at least significantly in the remaining areas.

Rates of contribution from both assessment perspectives could be retraced to indicators from the social system, economic system, and natural system, the first two being systems where the majority of factors that worsened ecological security originated, which, in essence, confirmed our assumption on the criterion layer from the indicator layer. Social-economic-natural coordinated development was the fundamental way to maintain ecological security. However, assessment results indicated that unreasonable or excessive social and economic development on the typical steppe ecoregion had gone far beyond what the region could bear, or specifically, anthropogenic activity was the origin of worsening ecological security in the typical steppe ecoregion.

\section{Discussion}

In the study of the typical steppe ecoregion, having analyzed panel data collected from four administrative regions between 2001 and 2010, Li et al. reported that local ecological security was at risk based on ecological footprint data, and that local economic development driven by food and energy production and exportation had exceeded the carrying capacity of the land, which was the major driving factor that worsened the ecological security situation [26]. Research findings by Li et al. were basically corroborated by the analytical results obtained from this study, but a comparison between these two studies is necessary. Our study's assessment has several advantages:

1) The longer 25 consecutive year assessment timeframe (1990-2014).

2) Both assessment indicators and results were measured using spatiotemporal data that better showed spatiotemporal variation in changes to the ecological security situation in the study area.
3) Compared to ecological footprint data, our assessment indicator system offered a more complete summary of the noosystem, which was based on the fact that the effect of social, economic, and natural factors on ecological security could be recognized and quantified more comprehensively while providing guidance in regional planning.

4) We applied dynamic targets as part of grey target transformation, which determined the coordinated development in the noosystem.

5) Changing characteristics were revealed both microcosmically and macrocosmically from global and local perspectives, which, prior to this study, had always been overlooked.

As mentioned above, the major indicators that resulted in ecological deterioration were mostly social and economic ones, with natural causes taking a small proportion (even natural changes were highly likely attributed to long-term human disturbances [57-58]. In the study area, the total population increased from $278.5 \times 10^{3}$ in 1990 to $389.3 \times 10^{3}$ in 2014 , during which the GDP also grew by a factor greater than 100 from $456.3 \times 10^{6} \mathrm{RMB}$ to $51312.2 \times 10^{6} \mathrm{RMB}$ [48]. According to the assessment methods developed in this study, the authors argued that local rapid social and economic development have exceeded the bearing capacity and linking capability (particularly referred to pasture animal husbandry and mineral exploitation [26]) compatible to the natural system from the perspective of existing technologies and management levels, which further damaged the overall coordinating capability of the local noosystem. In view of the fact that local ecological security will further worsen as social and economic progress is made in the future, it is suggested that the local decision-making department take the relationship between development and protection seriously and not to overlook ecological security for purposes of economic growth, and that preserving ecological security is protecting productivity and the people's well-being [59-60].

Indicator system-based ecological security assessments have been widely used in a variety of assessment studies because they fully cover and reflect patterns and procedures of the noosystem, which was the main reason why it was employed in this study. According to the practical situation of the typical steppe ecoregion, the indicator system used in this study was constructed following a social-economic-natural complex ecosystem in conjunction with spatially distributed social and economic indicators to determine their comprehensive response within the noosystem. Indicator system construction must always make a tradeoff between integrity and indicator availability [61], Compared with indicator screening using a mathematical method [35], the indicator system constructed based on expert experience oriented to the steppe noosystem was able to reflect the principal aspects influencing local ecological security as a whole [25, 28]. As a result, it was an indicator system that was able to reach assessment targets. This system consisted of social, economic, and natural systems that characterized the 
essential requirements of the noosystem and interacted and intercommunicated with each other as both cause and effect [24, 32]. Therefore, the indicator system involving only the natural system was a lopsided understanding of ecological security [62]. On the other hand, there were a number of similar studies taking population density as one assessment indicator [23, 34, 63-64], whereas the authors argued that this indicator failed to present the synthetic pressure of population to noosystem other than the spatial distribution of population [65]. The steppe might be left with no settled population, but it was the place for other activities, such as grazing, which is why it was replaced by the pressure of population on the environment in this study. While taking the fact that it was difficult to measure spatialized pressure of population on the environment into account, the authors made some compromise in indicator availability while ensuring the integrity of the indicator system and described various indicators such as pressure of population on the environment, pressure of primary industry on the environment, and grazing pressure (see Appendix A) using a small amount of auxiliary data. Admittedly, there are great inadequacies with respect to the describing capability of those indicators that need further research, which is critical to improving the accuracy of assessment results.

For computing ecological security, Equation(1) was not applicable until original indicator values were converted into indicator assessment scores. However, grey target transformation provided adequate consideration to the diversity of such indicators and specified corresponding assessment targets for different indicator categories, even for dynamic targets in parts of the indicators. Targets originating from assessment objects better fit assessment objects; thus, indicator assessment scores would better fit actual situations. Moreover, indicator assessment scores were all dynamically considered in conjunction with the weight method [56] applied in this study to the objective analysis of weights of various indicators. Although this method favorably reflected patterns and associations between various factors in the noosystem, it remained inadequate. That is to say, this method was too sensitive for indicators with major fluctuations to neglect relatively stable indicator effects. As a result, the weight method should not be the only one used. Instead, it is more important to employ appropriate weight methods based on different regions and specific indicators when investigating ecological security assessments.

In this study, we conducted an ecological security assessment of the typical steppe ecoregion from both global and local perspectives. The local perspective stressed spatial heterogeneity (climatic, anthropogenics, and so on), which is a perspective that previous studies had never incorporated [23-24, 30]. To obtain a more complete and comprehensive understanding of the changing characteristics of ecological security situations or others, it is better to consider changes in assessment objects from both perspectives. For example, accumulated years of the ESSI for West Ujimqin Banner was 0.8403, which ranked first among the various areas, suggesting that the local ecological security situation was higher compared to other areas. On the other hand, accumulated years of the ESSI for this area was 0.7647 from the local perspective, which ranked last among the various areas, indicating that the local ecological security situation in this area was worse compared to its optimal historical state. When the local perspective is removed from results, some information may be left out in assessment results that could not be readily detected. In cases where spatial heterogeneity in the assessment area was too complex and there were vast differences between various sectors such as nature and society, the global perspective should be used with caution because target sequences and indicator weights alone may not favorably estimate ecological security situations of all assessment objects. The local perspective, conversely, can be applied to any condition of spatial heterogeneity and avoid a mismatch between target sequences and indicator weights since it only targets individual assessment objects.

\section{Conclusions}

Nowadays, ecological security assessment is still in the initial stage, and its application for the steppe/grassland is rare. In view of this, a typical steppe ecoregion in Inner Mongolia was selected as the representative zone of grasslands of northern China. We constructed an indicator system constituting 25 specific indicators based on the local noosystem, introducing innovative computational methods and configuring two evaluation perspectives. The main points in this study are as follows:

First, from the global perspective, ESSIs continued to decline from approximately 0.9 to 0.7 from 1990 to 2014, and more than half of the area changed to "good" and "medium" levels during the latter stage. Similarly, situation indexes from the local perspective also declined continuously, by a factor of 2 to 3 compared to the declining rate exhibited in the global perspective, and this was because it fit assessment objects better. Therefore, the ecological situation worsened under the local perspective, with situation indexes even falling below 0.6 during the middle and latter stages, during which time "medium" and "poor" levels became the majority.

Second, according to the long-term mean annual values under the global perspective, the order of ecological security situation for the various areas that constitute the research region was (in descending order) West Ujimqin Banner $>$ Abag Banner $>$ East Ujimqin Banner $>$ Xilinhot City. According to long-term mean annual values under the local perspective, the order of the deteriorating degree of ecological security for the various areas that constitute the research region was (in descending order) West Ujimqin Banner $>$ East Ujimqin Banner $>$ Xilinhot City $>$ Abag Banner. Assessment results from both perspectives indicated that areas with favorable ecological security situations could also deteriorate significantly, such as West Ujimqin Banner. Conversely, areas where ecological security situations were less favorable could deteriorate only slightly, such as Xilinhot City. 
Third, the development of social and economic systems was the principal factor that led to the deterioration in ecological security, with an accumulated contribution from $80 \%$ to $90 \%$. Given that the effect of the economic system was greater by a factor of 2 to 3 compared to the social system, excessively rapid or vigorous economic development poses a significant threat to local ecological security. In particular, the excessive rural population put a heavy burden on the steppe of West Ujimqin Banner, East Ujimqin Banner, and Abag Banner, and the unreasonable development (mainly grazing and mining) is the most important factor to accelerate the deterioration of ecological security of the whole typical steppe ecoregion. Some individual indicators of the natural system also resulted in the deterioration of ecological security, but they were subsidiary and proportionally insignificant.

\section{Acknowledgements}

This work was funded by the National Key Basic Research Program of China (2014CB138803); the National Natural Science Foundation of China (31570451); the National Key R\&D Plan (2016YFC0500502), the Program for Changjiang Scholars and Innovative Research Team in University (IRT_15R06).

\section{Appendix A}

The ecological security assessment indicator system contains a part of the statistical indicators that are a numerical reflection of the whole condition of a single administrative district, while it lacks corresponding internal distribution information. To this end, the spatial distribution of this indicator value within an administrative district was realized according to characteristics of indicator attributes by relying on land-use category distribution maps (1990, 1995, 2000, 2005, and 2010; resdc.cn), with distribution processes emphasizing actual interactions between statistical indicators and the noosystem. Specifically, the four approaches used for the spatial distribution of statistical indicators are as follows [66]:

A) Effectual indicators must exert an overall effect on the eco-environment, such as environmental pressure from secondary industry $\left(C_{7}\right)$ that, being centered on mineral exploitation, consumed vast amounts of minerals and fresh water while generating waste water, waste residue, and waste gases that were then discharged into the atmosphere and caused widespread pollution, affecting various natural biospheric cycles. Therefore, environmental pressure that results from secondary industry is a typical type of pressure, and the indicators are numerically (or evenly) allocated to grids covering corresponding administrative districts.

B) Effectual indicators should exert local effects on the eco-environment, such as environmental pressure from the primary industry $\left(C_{6}\right)$ for which steppe livestock husbandry predominates. The production of livestock and its corresponding environmental impacts have mainly been concentrated on land designated for farming and grazing, while other land-use types, such as urban land, remain free from such pressure. As a result, environmental pressure from primary industry can be calculated by means of the equal distribution of production values of primary industry on specific land-use types, such as farming and grazing land. Eco-environmental pressure of similar indicators were also concentrated on their respective land-use categories.

C) Effectual indicators must specifically refer to the spatial distribution approach of population pressure on the environment. The population of the typical steppe ecoregion was divided into rural and urban populations for statistical analysis, which was based on the distribution of spatial environmental pressure according to their actual production and residential characteristics. Given that it is difficult to measure environmental pressure resulting from a unit population, which is also subject to changes in population size [65], grids supported simplified population sizes to represent population pressure on the environment. Rural population pressure on the environment is derived from two types of stress: untreated domestic waste that is discharged directly into residential environments and production and operation activities, such as grazing, that place direct environmental pressure on farming and grazing land, both of which occur simultaneously in different areas under varied unit environmental pressure. Therefore, rural population pressure on the environment is expressed by evenly distributing rural populations into these two different land-use types. Urban population pressure on the environment corresponds to environmental pressure from lifestyle activities, whereas environmental pressure generated from production and operation corresponds to industrial structures, investment scales, and technical levels rather than urban population size. Therefore, urban population pressure on the environment that derives from lifestyle activities can be calculated by evenly distributing urban populations on urban land. Table S1 provides land-use categories that correspond to the distribution of environmental pressure from rural and urban populations on the typical steppe ecoregion.

D) Table S1 is located here.

E) This approach specifically relates to the spatial distribution of grazing pressure $\left(C_{9}\right)$, that is, the amount of pasture that livestock requires per unit area. Given that livestock was divided into large livestock and sheep (including a small number of goats) in official statistics, we reallocated all livestock into a standard sheep unit according to the Inner Mongolia Autonomous Region Basic Steppe Protection Regulations (2016), with one 
Table S1. Distribution design of population pressure on the environment of the typical steppe ecoregion.

\begin{tabular}{|c|c|c|}
\hline $\begin{array}{c}\text { Land-use } \\
\text { category }\end{array}$ & Rural population & Urban population \\
\hline $\begin{array}{c}\text { Production } \\
\text { land }\end{array}$ & $\begin{array}{c}\text { Woodland, shrubland, open forest land, other woodland types, high coverage grassland, } \\
\text { moderate coverage grassland, low coverage grassland, sand, saline and alkaline land, } \\
\text { marshland, paddy land in hilly areas, hilly farmland, flat farmland, and sloped farmland }\end{array}$ & \\
\hline $\begin{array}{c}\text { Populated } \\
\text { land }\end{array}$ & Rural residential area & $\begin{array}{c}\text { Urban land, and land used for } \\
\text { other construction purposes }\end{array}$ \\
\hline
\end{tabular}

individual sheep being equal to one sheep unit and one large livestock (mainly cattle) being equal to five sheep units. Due to the limited spatial information available on livestock distribution, this was simplified into even distributions of livestock on farming and grazing land in various administrative districts (in the same way that production land was simplified for rural populations; Table S1) based on pasture area that a standard sheep unit requires within a specified space (grazing pressure), and it was calculated using the net primary productivity $\left(\mathrm{NPP}, C_{22}\right.$ ) of the current year.

\section{Appendix B}

The target is an optimal situation of ecological security, therefore the target setting relates to the accuracy of the indicator assessment score. Due to the diversity and complexity of the indicator system, the targets of various indicators were set as values that were closest to the state of ecological security under the following three categories:

The first category is a constant value. A single value serves as the target of an indicator.

The second category is a variable with a nonfixed value. Take, for example, population. The key to measuring population growth lies in the estimation of "threshold," which can then be used as a scale to evaluate differences between population growth and the ideal state of ecological security. In this study, the "threshold" was the rate of variation between two comparable years, which can be expressed using the following formula

$$
C_{\mu}=\frac{\chi_{\mu}-\chi_{\mu-1}}{\chi_{\mu-1}}(\mu=1991,1992, \cdots, 2014)
$$

...where $C_{\mu}$ is the rate of variation during the $\mu^{\text {th }}$ year, and $\chi_{\mu-1}$ and $\chi_{\mu}$ are indicator attribute values in the $(\mu-1)^{\text {th }}$ year and the $\mu^{\text {th }}$ year, respectively. In order to avoid disturbances from extreme events, this study used a rate of variation sequence from $5 \%$ to $95 \%$ intervals to obtain its mean values, which served as the "threshold" during the assessment process.

Variable values were further divided into two categories: the upper limit and the lower limit. We obtained yearly target values to be assessed using a base indicator value (typically the 1990 indicator value) and the rate of variation. For the upper limit category, the indicator value could not be greater than the target value of the same year; and for the lower limit category, the opposite was true. In the event that these requirements were met, the grey target transformation score was 1 ; otherwise, it was determined using Eq. (4).

The third category is the interval value. If the indicator value was within this interval, grey transformation output was 1 . Meanwhile, if this value was less than the lower limit of the interval or greater than its upper limit, grey transformation output was determined using Eq. (4) based on this value as well as the upper/lower limits. Given

Table S2. Target configuration categories of the ecological security assessment indicators.

\begin{tabular}{|c|c|c|c|c|c|}
\hline Code & Target category & Code & Target category & Code & Target category \\
\hline$C_{1}$ & Variable value-upper limit category & $C_{10}$ & Variable value-upper limit category & $C_{19}$ & Interval value-fixed value \\
\hline$C_{2}$ & Variable value-lower limit category & $C_{11}$ & Variable value-upper limit category & $C_{20}$ & Interval value-fixed value \\
\hline$C_{3}$ & Variable value-upper limit category & $C_{12}$ & Variable value-upper limit category & $C_{21}$ & Constant value-max value \\
\hline$C_{4}$ & Variable value-upper limit category & $C_{13}$ & Variable value-upper limit category & $C_{22}$ & Constant value-max value \\
\hline$C_{5}$ & Variable value-upper limit category & $C_{14}$ & Variable value-upper limit category & $C_{23}$ & Constant value-max value \\
\hline$C_{6}$ & Variable value-upper limit category & $C_{15}$ & Interval value-statistical value & $C_{24}$ & Constant value-max value \\
\hline$C_{7}$ & Variable value-upper limit category & $C_{16}$ & Interval value-statistical value & $C_{25}$ & Constant value-max value \\
\hline$C_{8}$ & Variable value-upper limit category & $C_{17}$ & Interval value-statistical value & & \\
\hline$C_{9}$ & Constant value-max value & $C_{18}$ & Interval value-statistical value & & \\
\hline
\end{tabular}


Table S3. Ecological security situation levels.

\begin{tabular}{|c|c|c|c|}
\hline No. & $\begin{array}{c}\text { Numerical } \\
\text { interval }\end{array}$ & Level & State description \\
\hline I & $0.9-1.0$ & Excellent & $\begin{array}{l}\text { The social-economic-natural complex ecosystem coordinately developed best of all, exhibiting stable } \\
\text { functions and structures and elasticity in the various subsystems; the state of the natural } \\
\text { eco-environment was favorable when it did not experience major natural disasters or extreme } \\
\text { climatic events; economic and social development did not endanger natural courses or ecological } \\
\text { balances, and human welfare improved overall. }\end{array}$ \\
\hline II & $0.8-0.9$ & Good & $\begin{array}{l}\text { A part of the social-economic-natural complex ecosystem did not coordinately develop, although it } \\
\text { exhibited basically stable functions and structures and certain elasticity in the various subsystems; } \\
\text { the natural ecosystem exhibited slight degradation, and natural disasters or major climatic events } \\
\text { occurred on occasion but with limited impact; economic and social development as a whole did not } \\
\text { interfere with natural courses or ecological balances, and human welfare improved continuously. }\end{array}$ \\
\hline III & $0.7-0.8$ & Medium & $\begin{array}{l}\text { The social-economic-natural complex ecosystem encountered problems related to coordinated } \\
\text { development, exhibiting increasing phenomena pertaining to functional and structural disorder, but } \\
\text { certain elasticity remained in various subsystems; the natural eco-environment degraded slightly, } \\
\text { with increasingly intensifying natural disasters or major climatic events; economic and social } \\
\text { development endangered natural courses and ecological balances. Although human welfare may see } \\
\text { improvement at the present time, it decreased in conjunction with long-term progress. }\end{array}$ \\
\hline IV & $0.6-0.7$ & Poor & $\begin{array}{l}\text { A sharp regression in the coordination of the social-economic-natural complex ecosystem, and the } \\
\text { loss in integration was greater than } 30 \% \text {, exhibiting severe functional and structural disorder; the } \\
\text { degradation of the natural eco-environment worsened, and natural disasters or major climatic events } \\
\text { further impaired coordinated processes; economic and social development caused severe degradation } \\
\text { to natural courses and ecological balances, while human welfare suffered from these adverse effects } \\
\text { and did not improve. }\end{array}$ \\
\hline $\mathrm{V}$ & $<0.6$ & $\mathrm{Bad}$ & $\begin{array}{l}\text { The social-economic-natural complex ecosystem encountered significant obstacles in its overall } \\
\text { coordinated development, and integration loss was greater than } 40 \% \text {, where functions and structures } \\
\text { nearly collapsed; the natural eco-environment severely degraded with an ultimate loss in natural } \\
\text { regulatory capacity and suffered frequent natural disasters or extreme climatic events; economic and } \\
\text { social development stagnated, natural courses and ecological balances collapsed, and human welfare } \\
\text { declined and, in extreme cases, human existence was endangered. }\end{array}$ \\
\hline
\end{tabular}

that targets of meteorological indicators were mostly interval values, we calculated the numerical interval where the target was positioned based on data from a number of decades prior to 1990 so that the data would not be affected by the climate changes that have occurred in recent decades. When exception values were rejected using data from the $5 \%$ to $95 \%$ interval, we calculated mean values $(\bar{\chi})$ and standard deviations $(\delta)$ to obtain target intervals, that is, $[\bar{\chi}-\delta, \bar{\chi}+\delta]$. Apart from the statistical category, interval values could also be a fixed category when targets of certain indicators were within a fixed numerical interval; for example, the target of the annual drought index was within $[-1,1]$.

Table S2 lists the categories of various targets according to the classification of the above three target categories.

\section{Appendix C}

Table S3.

\section{References}

1. SHAVAEV A.X. New Theory of National Security. Beijing: Yi Wen Publishing Military, 2002.

2. WU J. Landscape sustainability science: ecosystem services and human well-being in changing landscapes. Landscape Ecology, 28 (6), 999, 2013.
3. BARRETT G.W. A problem-solving approach to resource management. Bioscience, 35 (7), 423, 1985.

4. MA S., WANG R. The Social-Economic-Natural Complex Ecosystem. Acta Ecologica Sinica, 4 (1), 1, 1984.

5. ŠLAUS I., JACOBS G. Human Capital and Sustainability. Sustainability, 3 (12), 97, 2011.

6. WARNER K., HAMZA M., OLIVER-SMITH A., RENAUD F., JULCA A. Climate change, environmental degradation and migration. Natural Hazards, 55 (3), 689, 2009.

7. WANG P., LASSOIE J.P., MORREALE S.J., DONG S. A critical review of socioeconomic and natural factors in ecological degradation on the Qinghai-Tibetan Plateau, China. The Rangeland Journal, 37 (1), 1. 2015.

8. ZIKA M., ERB K.-H. The global loss of net primary production resulting from human-induced soil degradation in drylands. Ecological economics, 69 (2), 310, 2009.

9. BORUCKE M., MOORE D., CRANSTON G., GRACEY K., IHA K., LARSON J., GALLI A. Accounting for demand and supply of the biosphere's regenerative capacity: The National Footprint Accounts' underlying methodology and framework. Ecological Indicators, 24, 518, 2013.

10. CARDINALE B.J., DUFFY J.E., GONZALEZ A., HOOPER D.U., PERRINGS C., VENAIL P., NAEEM S, Biodiversity loss and its impact on humanity. Nature, 486 (7401), 59, 2012.

11. COSTANZA R., D'ARGE R., DE GROOT R., FARBER S., GRASSO M., HANNON B., O'NEILL R.V. The value of the world's ecosystem services and natural capital. Nature, 387 (387), 253, 1997. 
12. QU G. The problems of ecological environmental have become a popular subject of country safety. Environmental Protection, 5, 3, 2002.

13. LIU D., CHANG Q. Ecological security research progress in China. Acta Ecologica Sinica, 35 (5), 111, 2015.

14. COHEN J.E., TILMAN D. Biosphere 2 and biodiversity: The lessons so far. Science, 274 (5290), 1150, 1996.

15. PARROTT L. Measuring ecological complexity. Ecological Indicators, 10 (6), 1069, 2010.

16. BURKHARD B., KROLL F., NEDKOV S., MÜLLER F. Mapping ecosystem service supply, demand and budgets. Ecological Indicators, 21, 17, 2012.

17. WU J. Landscape Ecology: Pattern, Process, Scale and Hierarchy $\left(2^{\text {nd }}\right.$ ed.). Beijing: Higher Education Press, 2007.

18. GAO J., ZHANG X., JIANG Y., OU X., HE D., SHI J. Key issues on watershed ecological security assessment. Chinese Science Bulletin, 52 (2), 251, 2007.

19. MAYER A.L. Strengths and weaknesses of common sustainability indices for multidimensional systems. Environment international, 34 (2), 277, 2008.

20. SINGH R.K., MURTY H.R., GUPTA S.K., DIKSHIT A.K. An overview of sustainability assessment methodologies. Ecological Indicators, 15 (1), 281, 2012.

21. BAI X., TANG J. Ecological security assessment of Tianjin by PSR model. Procedia Environmental Sciences, 2, 881, 2010.

22. XU L., YIN H., LI Z., LI S. Land Ecological Security Evaluation of Guangzhou, China. International Journal of Environmental Research and Public Health, 11 (10), 10537. 2014.

23. WANG H., LONG H., LI X., YU F. Evaluation of changes in ecological security in China's Qinghai Lake Basin from 2000 to 2013 and the relationship to land use and climate change. Environmental Earth Sciences, 72 (2), 341, 2014

24. ZHANG J., GAO J. Lake ecological security assessment based on SSWSSC framework from 2005 to 2013 in an interior lake basin, China. Environmental Earth Sciences, 75 (10), 1, 2016.

25. HAN B., LIU H., WANG R. Urban ecological security assessment for cities in the Beijing-Tianjin-Hebei metropolitan region based on fuzzy and entropy methods. Ecological Modelling, 318, 217, 2015.

26. LI X., TIAN M., WANG H., WANG H., YU J. Development of an ecological security evaluation method based on the ecological footprint and application to a typical steppe region in China. Ecological Indicators, 39 (April), 153, 2014.

27. CHEN H.-S. Evaluation and Analysis of EcoSecurity in Environmentally Sensitive Areas Using an Emergy Ecological Footprint. International Journal of Environmental Research and Public Health, 14 (2), 136, 2017.

28. SU S., CHEN X., DEGLORIA S. D., WU J. Integrative fuzzy set pair model for land ecological security assessment: a case study of Xiaolangdi Reservoir Region, China. Stochastic Environmental Research and Risk Assessment, 24 (5), 639, 2009.

29. SU S., LI D., YU X., ZHANG Z., ZHANG Q., XIAO R., WU J. Assessing land ecological security in Shanghai (China) based on catastrophe theory. Stochastic Environmental Research and Risk Assessment, 25 (6), 737, 2011.

30. LIANG W., ZHENGFU B., HONGQUAN C. Land ecological security assessment for Yancheng city based on catastrophe theory. Earth Sciences Research Journal, 18 (2), 181, 2014
31. FENG Y., LIU Y., LIU Y. Spatially explicit assessment of land ecological security with spatial variables and logistic regression modeling in Shanghai, China. Stochastic Environmental Research and Risk Assessment, 1, 2016.

32. XU C., PU L., ZHU M., LI J., CHEN X., WANG X., XIE X. Ecological Security and Ecosystem Services in Response to Land Use Change in the Coastal Area of Jiangsu, China. Sustainability, 8 (8), 816, 2016.

33. GONG J., LIU Y., XIA B., ZHAO G. Urban ecological security assessment and forecasting, based on a cellular automata model: A case study of Guangzhou, China. Ecological Modelling, 220 (24), 3612, 2009.

34. SUN L., LIU Z., ZHENG M., CAI Q., FANG H. Temporal variations of ecological security with soil and water loss stress in black soil region of northeast China: a case study on Baiquan County. SpringerPlus, 2, S6, 2013.

35. MA T., ZHANG X., YANG Z., HAN F., SHI H., WANG C., LIU Q. Plateau Mountain Eco-Security Early Warning Research. Polish Journal of Environmental Studies, 25 (3), 2016.

36. CHEN Y., LI Z., LI W., DENG H., SHEN Y. Water and ecological security: dealing with hydroclimatic challenges at the heart of China's Silk Road. Environmental Earth Sciences, 75 (10), 1, 2016.

37. KANG L., HAN X., ZHANG Z., SUN O. J. Grassland ecosystems in China: review of current knowledge and research advancement. Philosophical Transactions of the Royal Society B: Biological Sciences, 362 (1482), 997, 2007.

38. FAY P.A., KAUFMAN D.M., NIPPERT J.B., CARLISLE J.D., HARPER C.W. Changes in grassland ecosystem function due to extreme rainfall events: implications for responses to climate change. Global Change Biology, 14 (7), 1600, 2008.

39. HILKER T., NATSAGDORJ E., WARING R.H., LYAPUSTIN A., WANG Y. Satellite observed widespread decline in Mongolian grasslands largely due to overgrazing. Global Change Biology, 20 (2), 418, 2014.

40. DONG X., DAI G., ULGIATI S., NA R., ZHANG X., KANG M., WANG X. On the Relationship between Economic Development, Environmental Integrity and Well-Being: The Point of View of Herdsmen in Northern China Grassland. PLoS ONE, 10 (9), 2015.

41. WANG S., WILKES A., ZHANG Z., CHANG X., LANG R., WANG Y., NIU H. Management and land use change effects on soil carbon in northern China's grasslands: a synthesis. Agriculture, Ecosystems Environment, 142 (34), 329, 2011.

42. PAN D., JIA H., YUAN Y. A GIS-Based Ecological Safety Assessment of Wushen Banner, China. Human and Ecological Risk Assessment, 21 (2), 297, 2014.

43. LI B. The Rangeland Degradation in North China and Its Preventive Strategy. Scientia Agricultura Sinica, 30 (6), 1, 1997.

44. DA L., ZHENG Y. Pastoral Areas and Market: A Herderbased Economics. Beijing: Social Sciences Academic Press(China), 2010.

45. ZHANG Q., WU S., ZHAO D., DAI E. Temporal-spatial Changes in Inner Mongolian Grassland Degradation during Past ThreeDecades. Agricultural Science Technology, 14 (4), 676, 2013

46. LOWE G.D., PINHEY T.K., GRIMES M.D. Public Support for Environmental Protection New Evidence from National Surveys. Sociological Perspectives, 23 (4), 423, 1980.

47. SHEN J. Meteorological disaster records of China: Inner Mongolia. Beijing: China Meteorological Press, 2008. 
48. IMARBS. Inner Mongolia Statistical Yearbook. Beijing: China Statistics Press. 1991-2015.

49. HUTCHINSON M. Anusplin version 4.36 user guide. Canberra: Australian National University, 2006.

50. VICENTE-SERRANO S. M., BEGUERÍA S., LÓPEZMORENO J.I. A Multiscalar Drought Index Sensitive to Global Warming: The Standardized Precipitation Evapotranspiration Index. Journal of Climate, 23 (7), 1696, 2009.

51. LIU Z., WANG Y. Husbandry Climatic Regionalization of Xilin Gol League in Inner Mongolia. Beijing: China Meteorological Press, 2006.

52. ZHU W., PAN Y., ZHANG J. Estimation of Net Primary Productivity of Chinese Terrestrial Vegetation Based on Remote Sensing. Journal of Plant Ecology, 31 (3), 413, 2007.

53. GUTMAN G., IGNATOV A. The derivation of the green vegetation fraction from NOAA/AVHRR data for use in numerical weather prediction models. International Journal of Remote Sensing, 19 (8), 1533, 1998.

54. ZHAN J. Impacts of Land-use Change on Ecosystem Services. Berlin: Springer, 2015.

55. XIAO X., MAO S. Grey Prediction and Decision-making Method. Beijing: Science Press, 2013.

56. WANG Y. Comprehensive Assessment Method and Application of Overall Effectiveness. Science Technology Progress and Policy, 17 (4), 127, 2000.

57. PIELKE R.A., PITMAN A., NIYOGI D., MAHMOOD R., MCALPINE C., HOSSAIN F., DE NOBLET N. Land use/land cover changes and climate: modeling analysis and observational evidence. Wiley Interdisciplinary Reviews: Climate Change, 2 (6), 828, 2011.
58. SOLOMON S., PLATTNER G.K., KNUTTI R., FRIEDLINGSTEIN P. Irreversible climate change due to carbon dioxide emissions. Proc Natl Acad Sci U S A, 106 (6), 1704, 2009.

59. BARBIER E. The policy challenges for green economy and sustainable economic development. Natural Resources Forum, 35 (3), 233, 2011.

60. WANG S., MENG W., JIN X., ZHENG B., ZHANG L., XI $\mathrm{H}$. Ecological security problems of the major key lakes in China. Environmental Earth Sciences, 1, 2015.

61. DOREN R.F., TREXLER J.C., GOTTLIEB A.D., HARWELL M.C. Ecological indicators for system-wide assessment of the greater everglades ecosystem restoration program. Ecological Indicators, 9 (6), S2, 2009.

62. ZHANG H., XU E. An evaluation of the ecological and environmental security on China's terrestrial ecosystems. Sci Rep, 7 (1), 811, 2017.

63. ZHAO C., ZHOU B., SU X. Evaluation of Urban EcoSecurity - A Case Study of Mianyang City, China. Sustainability, 6 (4), 2281, 2014.

64. LI F., LU S., SUN Y., LI X., XI B., LIU W. Integrated Evaluation and Scenario Simulation for Forest Ecological Security of Beijing Based on System Dynamics Model. Sustainability, 7 (10), 13631, 2015.

65. EHRLICH P.R., HOLDREN, J. P. Impact of population growth. Science, 171 (3977), 1212, 1971.

66. SHAKER R.R. The spatial distribution of development in Europe and its underlying sustainability correlations. Applied Geography, 63, 304, 2015. 
